\title{
AS CRÍTICAS DE HABERMAS A RAWLS ACERCA DO DIÁLOGO ENTRE SECULARISMO E RELIGIÃO NA DEMOCRACIA
}

\author{
HABERMAS'S CRITICISM TO RAWLS ABOUT THE DIALOGUE BETWEEN SECULARISM AND \\ RELIGION IN DEMOCRACY
}

Juliano Cordeiro da Costa Oliveira*

\section{RESUMO}

O artigo debate as críticas que Jürgen Habermas faz a John Rawls acerca do diálogo entre secularismo e religião na democracia. Enquanto Rawls defende uma divisão estrita, nos sujeitos, entre identidades religiosas e não religiosas, Habermas adota a estratégia da tradução da linguagem religiosa para uma secular, e não propriamente uma divisão entre identidades religiosas e não religiosas, embora conserve o elemento formal e kantiano da ética. Desta forma, enfatizaremos, primeiramente, em Rawls, a modificação teórica ocorrida entre a obra Uma Teoria da Justiça para o Liberalismo Político, uma vez que tal mudança torna-se fundamental para a proposta de Rawls acerca do diálogo entre secularismo e religião na democracia. Em Uma Teoria da Justiça, a razão pública é dada por uma doutrina liberal abrangente, enquanto no Liberalismo Político é proposta uma maneira de argumentar sobre valores políticos compartilhados por cidadãos livres e iguais, levando em conta suas doutrinas abrangentes, desde que estas sejam compatíveis com uma sociedade democrática. Finalmente, destacaremos as críticas de Habermas à ideia rawlsiana da posição original, tendo consequências em sua crítica posterior à proposta de Rawls de separação entre identidades religiosas e não religiosas nos sujeitos que deliberam. Habermas considera que há, em Rawls, um fardo adicional indevido que exige uma partição da identidade num aspecto público e noutro privado. Segundo Habermas, haveria, em Rawls, uma sobrecarga mental e psicológica insuportável para os religiosos, prejudicando as necessárias condições simétricas de participação na democracia.

PALAVRAS-CHAVE: Habermas. Rawls. Religião. Secularismo.

\section{ABSTRACT}

The article debates the criticism that Jürgen Habermas makes to John Rawls about the dialogue between secularism and religion in democracy. While Rawls advocates a strict division in subjects between religious and non-religious identities, Habermas adopts the translation strategy of religious language into a secular, not exactly a division between religious and non-religious identities, although retaining the formal and Kantian element of ethics. Thus, we will emphasize, firstly, in Rawls, the

\footnotetext{
* Doutorando em Filosofia pela Universidade Federal do Ceará (UFC), com doutorado sanduiche na LudwigMaximilians-Universität, em Munique, Alemanha. Bolsista Capes. E-mail: julianocordeiro81@ gmail.com.
} 
theoretical change occurred between the work A Theory of Justice to Political Liberalism, since such a change is fundamental to Rawls' proposal about the dialogue between secularism and religion in democracy. In A Theory of Justice, the public reason is given by a comprehensive liberal doctrine, while in Political Liberalism it is proposed a way to argue about political values shared by free and equal citizens, taking into account their comprehensive doctrines, since these are compatible with a democratic society. Finally, we will highlight Habermas' criticism to Rawlsian's ideas of the original position, with consequences in his later criticism of the proposal to Rawls separation between religious and non-religious identities in individuals who take decisions. Habermas believes that there is, in Rawls, improper additional burden that requires a partition of identity in a public and another private aspect. According to Habermas, there would be, in Rawls, a mental and psychological burden, unbearable for the religious people, which would damage the necessary symmetrical conditions of participation in democracy.

KEYWORDS: Habermas. Rawls. Religion. Secularism.

\section{INTRODUÇÃO}

John Rawls parte, assim como Jürgen Habermas, de uma questão essencial, a saber: como é possível existir, ao longo do tempo, uma sociedade estável e justa de cidadãos livres e iguais que se encontram profundamente divididos por doutrinas religiosas, filosóficas e morais razoáveis, embora incompatíveis entre si? Em Rawls, uma concepção política de justiça deve se sustentar por si própria, cuja formulação não deriva nem é parte de nenhuma doutrina abrangente. Tal concepção de justiça tem de conter seu próprio ideal normativo intrínseco (RAWLS, 2011).

Rawls explica que é desejável que as doutrinas filosóficas, religiosas e morais abrangentes, às quais estamos habituados a recorrer para debater questões políticas fundamentais, sejam deixadas de lado na vida pública. Portanto, as argumentações sobre os elementos constitucionais devem ser guiadas por princípios e valores que todos podem aceitar como razoáveis, estando na ordem do político, e não do metafísico.

Todavia, Habermas critica a estratégia rawlsiana de separar, num mesmo indivíduo, uma identidade pública de uma privada, no debate entre secularismo e religião na democracia. Em Habermas, não há uma separação estrita entre identidade pública e privada, como existe em Rawls. Na perspectiva habermasiana, haveria, em Rawls, uma sobrecarga mental e psicológica insuportável para os religiosos, prejudicando as necessárias condições simétricas de participação na democracia (HABERMAS, 2007). 


\section{A IDEIA DA RAZÃO PÚBLICA EM JOHN RAWLS: DA TEORIA DA JUSTIÇA AO LIBERALISMO POLÍTICO.}

A tarefa determinante do pensamento rawlsiano, em sua última fase, em 1993, no Liberalismo Político, é o da justificação de uma concepção autônoma ou independente da justiça política em sociedades pluralistas (RAWLS, 2011). Porém, Rawls, em Uma Teoria da Justiça (obra de 1971), não distinguia claramente entre o que seria uma concepção política, de um lado, e uma doutrina abrangente, de outro, possuindo elementos desta última sob a forma de uma concepção filosófica e moral ampla, projetada no domínio do político, o que a tornava incompatível com o fato do pluralismo e com a proposta rawlsiana de um construtivismo político que pudesse ser distinguido de uma doutrina abrangente (RAWLS, 2008).

Segundo o próprio Rawls, Uma Teoria da Justiça tenta desenvolver, a partir da ideia do contrato social, uma perspectiva que se torne a melhor aproximação de nossos "juízos ponderados de justiça e, portanto, forneça a base moral mais adequada para uma sociedade democrática" (RAWLS, 2011, p. 582). A proposta normativa rawlsiana é apresentada ainda, na Teoria da Justiça, como uma doutrina liberal abrangente, embora o termo "doutrina abrangente" não seja usado no livro. "Este tipo de sociedade contradiz o fato do pluralismo razoável e, em vista disso, O Liberalismo Político considera impossível essa sociedade" (RAWLS, 2011, p. 582).

O Liberalismo Político examina, por assim dizer, uma questão distinta da Teoria da Justiça, qual seja: como é possível para os que afirmam uma doutrina abrangente, religiosa ou não, sustentar uma concepção política razoável de justiça que forneça apoio a uma sociedade democrática institucional? Em Uma Teoria da Justiça, a razão pública é dada por uma doutrina liberal abrangente, enquanto no Liberalismo Político é proposta uma maneira de argumentar sobre valores políticos compartilhados por cidadãos livres e iguais, levando em conta suas doutrinas abrangentes, desde que estas sejam compatíveis com uma sociedade democrática.

No Liberalismo Político, Rawls se abstém de fazer afirmações acerca das doutrinas abrangentes. Estas não podem rejeitar, contudo, os elementos essenciais de um regime democrático. Em Rawls, podemos falar de doutrinas abrangentes irreconciliáveis, mas que sejam razoáveis, no sentido de respeitarem um mesmo sistema democrático. Rawls pretende estabelecer, em seu Liberalismo Político, a ideia de que é possível obter princípios de justiça válidos, aceitáveis para todos, à luz de um procedimento estruturado com base em certas 
ideias de uma sociedade democrática, independentemente de qualquer doutrina abrangente (religiosa ou secular), algo também pretendido por Habermas, como ainda veremos.

Segundo Rawls, uma doutrina abrangente razoável é aquela que não rejeita os princípios fundamentais de um regime democrático. Ele defende que, exceto no caso do fundamentalismo, as diversas religiões podem dar apoio a um regime democrático constitucional. "Isto é verdade para o catolicismo e para grande parte do protestantismo, do judaísmo e do islã” (RAWLS, 2011, p. 520).

Rawls explica que uma concepção política deve ser compartilhada por todos, enquanto que as doutrinas abrangentes não. Precisamos distinguir entre uma base pública de justificação sobre questões políticas fundamentais, que seja aceitável aos cidadãos em geral, e as muitas bases de justificação que não tem o caráter de públicas, que pertencem exclusivamente a diversas doutrinas abrangentes e, por isso, só são aceitáveis para os que subscrevem tais doutrinas.

A união social já não se funda em uma concepção do bem tal como dada por uma fé religiosa comum ou por uma doutrina filosófica, e sim em uma concepção pública e compartilhada de justiça apropriada à concepção dos cidadãos como pessoas livres e iguais em um Estado democrático. (RAWLS, 2011, p. 360).

Para Rawls, os elementos da concepção política de justiça devem se diferenciar dos elementos análogos das doutrinas abrangentes. O Liberalismo Político distingue a chamada razão pública das não públicas. Porém, não é suficiente que as doutrinas abrangentes aceitem um regime democrático somente como um modus vivendi. Antes, é preciso que o aceitem como participantes de um consenso sobreposto razoável. Rawls enfatiza que seu liberalismo político não é uma forma de liberalismo iluminista, isto é, uma doutrina liberal abrangente, de caráter secular. Ou seja, o liberalismo rawlsiano não professa o secularismo propriamente dito como uma visão de mundo ou ideologia.

\footnotetext{
O liberalismo político não tem tais objetivos. Considera como dado o fato do pluralismo razoável de doutrinas abrangentes. (...) O problema do liberalismo político é o de formular uma concepção política de justiça para um regime democrático constitucional que uma pluralidade de doutrinas razoáveis, tanto religiosas quanto não religiosas, possa livremente subscrever, e, assim, de maneira que possam ser livremente praticadas em conformidade com essa concepção e compreender suas virtudes. (RAWLS, 2011, p. 42).
}

Rawls diferencia, portanto, racional de razoável. O primeiro se aplica a um agente único que busca realizar fins e interesses particulares, dizendo também respeito à escolha de 
meios eficazes para obter um determinado fim. Já a razoabilidade relaciona-se com uma cooperação equitativa, sendo fundamentalmente algo público. Por meio da razoabilidade, afirma Rawls, entramos no mundo político. Ele trabalha com a ideia de uma justificação pública para um regime constitucional, e não com a ideia de uma verdade moral ligada a uma doutrina abrangente particular. Reiner Forst, nesse sentido, fala de um "princípio da justificação pública" (FORST, 2010, p. 153). Para ele, "uma teoria deontológica tem como cerne, portanto, um princípio procedimental de justificação” (FORST, 2010, p. 217), como há em Rawls.

Rawls afirma que os cidadãos possuem dois pontos de vista: um abrangente (privado) e outro político (público). A visão de um indivíduo poderia ser dividida em duas partes. Rawls destaca que é preciso embasar os elementos constitucionais essenciais e as instituições básicas de justiça unicamente nesses valores políticos, entendendo-os como a base da razão e da justificação pública, e não em doutrinas abrangentes específicas e particulares.

\begin{abstract}
O liberalismo político, então, aspira a uma concepção política de justiça entendida como uma visão que se sustenta por si própria. Ele não propõe nenhuma doutrina metafísica ou epistemológica específica que vá além daquilo que está envolvido na própria concepção política. Como uma interpretação de valores políticos, uma concepção política que se sustenta por si própria não nega a existência de outros valores que se aplicam, digamos, aos âmbitos do pessoal, do familiar ou da vida associativa; tampouco afirma que os valores políticos são separados de outros valores ou que estão em descontinuidade com outros valores (RAWLS, 2011, p. 12).
\end{abstract}

Devemos, para Rawls, distinguir entre o modo como uma concepção política é formulada, da possibilidade dela ser parte ou poder ser derivada de uma doutrina abrangente. Porém, uma concepção política "não envolve nenhum compromisso mais profundo com qualquer outra doutrina" (RAWLS, 2011, p. 15).

Rawls, assim, desenraiza o indivíduo, que precisa ser "arrancado" de dentro de sua doutrina abrangente e compreensiva, bem como trazido ao terreno do público e do razoável, sem sua tradição ou costume. Já na perspectiva habermasiana não há esse desenraizamento, e as idealizações de que se necessita para a construção das normas já estão presentes na linguagem daqueles que desde sempre se encontram inseridos em práticas comunicativas, indo contra a ideia rawlsiana da posição original. 


\title{
2 AS CRÍTICAS DE HABERMAS À POSIÇÃO ORIGINAL DE RAWLS.
}

O pressuposto conceitual no debate entre Rawls e Habermas se encontra na posição original, definida por Rawls da seguinte forma:

\begin{abstract}
A posição original é um dispositivo analítico empregado para formular uma conjectura, que é a de que quando perguntamos quais são os princípios mais razoáveis de justiça política para uma democracia constitucional cujos cidadãos são considerados livres e iguais, razoáveis e racionais, a resposta é que esses princípios são fornecidos por um dispositivo de representação no qual partes racionais (como representantes dos cidadãos, uma para cada cidadão) encontram-se situadas sob condições razoáveis e restringidas de forma absoluta por essas condições. Assim, é como se cidadãos livres e iguais chegassem eles próprios a um acordo sobre esses princípios políticos, sob condições que os representam como pessoas tanto razoáveis quanto racionais. (RAWLS, 2011, p. 451).
\end{abstract}

Na posição original, devemos imaginar uma situação na qual os contratantes devem escolher os princípios que governam sua associação política, colocados por trás de um véu da ignorância. Desta forma, não se pode ser influenciado por informações que digam respeito a sua situação particular. Isto garantiria, para Rawls, a imparcialidade do resultado da escolha. Entretanto, ele postula dois princípios de justiça que resultariam sempre da posição original: 1) Cada pessoa tem um direito igual ao mais amplo sistema de liberdades básicas iguais compatíveis com um sistema similar de liberdade para todos. 2) Desigualdades sociais e econômicas são admissíveis quando (a) promovem o maior benefício esperado aos menos favorecidos e (b) vinculadas a posições e cargos públicos abertos a todos sob condições de igualdade equitativa de oportunidades.

Porém, Habermas argumenta que Rawls ainda estaria preso a um egoísmo racional quando parte da posição original. Esta é considerada por Habermas como monológica, e não dialógica.

Mas enquanto aplicarmos esse exame mais pretensioso, restam perspectivas individuais isoladas, a partir das quais cada um de nós imagina privadamente o que todos poderiam querer. Isso é insatisfatório (HABERMAS, 2002, p. 71).

Habermas critica Rawls, o qual parte do princípio de que há pessoas isoladas que, antes do processo de socialização, dispõem da capacidade de percepção "teológico-racional dos seus interesses impondo seus objetivos nesse enquadramento monológico" (HABERMAS, 1991, p. 27). Ele, ao contrário de Rawls, vê o ponto de vista moral encarnado, desde sempre, no procedimento de uma argumentação intersubjetiva e linguisticamente 
articulada. Habermas destaca a centralidade dos mundos vividos na formação dos sujeitos, enquanto Rawls postularia indivíduos construídos antes do processo de socialização.

Nesse sentido, algumas das críticas dos comunitaristas a Rawls se assemelham muito às objeções de Habermas, embora este sempre defenda uma prioridade do justo frente ao bem, assim como o caráter formal e deontológico das normas. "Para os comunitaristas, os direitos individuais, embora básicos e primários, não podem ser deslocados da comunidade e encontrar sua ancoragem numa concepção abstrata da pessoa" (RAMOS, 1998, p. 235).

Segundo Habermas, o véu da ignorância de Rawls, desde o início, restringe o campo de visão das partes na posição original, presumindo, erroneamente, que cidadãos livres e iguais, sem contar com sua autocompreensão ou compreensão de mundos divergentes, iriam todos unir-se. A posição original rawlsiana corresponde a uma situação análoga à do estado de natureza no contratualismo clássico. Contudo, como critica Habermas, Rawls não demonstra nem justifica os motivos que fariam os indivíduos se unirem através de um contrato social, como fazem os modernos (HABERMAS, 2007).

Reiner Forst, por sua vez, faz uma crítica a Rawls semelhante à perspectiva habermasiana:

\footnotetext{
Porém, não estariam as pessoas orientadas de modo muito individualista em seus esforços por bens básicos (direitos e liberdades fundamentais, oportunidades sociais, renda e riqueza, as bases sociais do autorrespeito) e, portanto, não estariam demasiado abstraídas dos contextos sem os quais não faz sentido falar sobre a justiça? Com isso, não seriam os princípios de justiça resultantes da posição original tanto individualistas quanto abstratos excessivamente? (FORST, 2010, p. 16).
}

Segundo Habermas, Rawls faz uso de conceitos substanciais ao postular sua posição original, algo inviável para quem defende um conceito de justiça deliberativa. Por conseguinte, haveria, em Rawls, "uma vantagem dos direitos fundamentais liberais que chega de certa maneira a obscurecer o processo democrático" (HABERMAS, 2002, p. 83). Para ele, Rawls transforma os princípios de justiça, que poderiam ser interpretados procedimentalmente, em valores políticos substantivos que ninguém poderia razoavelmente rejeitar, dando privilégio à liberdade individual dos modernos, em contraposição à liberdade pública dos antigos.

De acordo com Habermas, há, em Rawls, determinados valores escolhidos antes mesmo do processo deliberativo e de socialização. Com a construção dos princípios de justiça na posição original, bem como sua conversão em valores políticos, encontraríamos uma 
antecipação de resultado do que deveria ser alcançado "na práxis de autodeterminação política dos cidadãos" (WERLE, 2012, p. 188). Rawls cairia numa construção monológica dos princípios de justiça, pois um indivíduo poderia por si mesmo tentar justificar as normas fundamentais, negando o princípio dialógico em que os sujeitos se encontram, desde sempre, encanados numa práxis comunicativa.

Portanto, Habermas critica a estratégia rawlsiana de separar, num mesmo indivíduo, uma identidade pública e uma privada, no debate sobre secularismo e religião na democracia. Ele opta, tal qual veremos no próximo tópico, por uma tradução do idioma religioso para o secular, garantindo o caráter procedimental de sua ética, sem desprezar o contexto formador das identidades dos sujeitos. Em Habermas, não há uma separação estrita entre identidade pública e privada, como existe em Rawls.

Habermas enfatiza que Rawls privilegia, na posição original, os direitos dos modernos, assumindo características a priori que rebaixam o processo democrático a um status inferior, haja vista a prioridade rawlsiana do indivíduo frente ao processo de socialização dos sujeitos: Rawls não realizaria a síntese entre autonomia privada e pública, como Habermas elabora no seu conceito de democracia deliberativa. Em Rawls, antes do consenso abrangente, não existe uma perspectiva pública, intersubjetivamente partilhada.

O que Rawls denomina uso público da razão já pressupõe o consenso básico antes do processo de socialização. Rawls, de acordo com Habermas, filia-se aqui muito mais ao pensamento de Hobbes do que ao de Kant, à medida que defende a posição de que o consenso público ocorre por meio de fundamentos privados, anteriores à intersubjetividade. Habermas, por isso, "entende razão como algo incorporado nos próprios atos linguísticos” (OLIVEIRA, 1998, p.95-6). Trata-se, em Rawls, ainda de um uso privado da razão, na intenção políticopública, e não de um uso público da razão no sentido estrito. E que implicações tudo isso tem para o problema do diálogo entre secularismo e religião em Rawls, a partir das críticas de Habermas?

\section{HABERMAS VERSUS RAWLS NA PROBLEMÁTICA DA RELIGIÃO E DO SECULARISMO.}

Rawls explicita que os católicos podem rejeitar uma decisão que garanta o direito ao aborto. Eles podem apresentar uma argumentação fundada na razão pública para rejeitar tal direito e não conseguir conquistar uma maioria. Mas eles não são obrigados a exercer o 
direito ao aborto no caso deles próprios. Podem reconhecer que o direito integra a lei legítima e, então, não devem lhe opor resistência através da força. Do contrário, significaria uma tentativa de impor uma doutrina abrangente específica, que uma maioria dos demais cidadãos não segue nem aceita.

É possível, contudo, aos católicos, em conformidade com a razão pública, continuar argumentando contra o direito ao aborto. Que a razão não pública da Igreja Católica requeira que seus membros sigam sua doutrina é plenamente compatível com a razão pública.

Quando os cidadãos se convertem a outra religião ou não professam mais uma fé religiosa, não deixam de ser, no que diz respeito a questões de justiça política, as mesmas pessoas de antes. Não há nenhuma perda de suas identidades públicas ou institucionais. Eles continuam conservando os mesmos direitos e deveres, podendo fazer as mesmas demandas de antes (RAWLS, 2011).

Sobre isso, Rawls cita o seguinte exemplo: no caminho para Damasco, Saulo de Tarso transforma-se em Paulo, o Apóstolo. No entanto, tal conversão não implica nenhuma mudança em nossa identidade pública ou institucional. De acordo com Rawls, para os propósitos de uma vida pública, Saulo de Tarso e o Apóstolo São Paulo são a mesma pessoa. "A conversão é irrelevante para nossa identidade pública ou institucional” (RAWLS, 2011, p. 38).

Rawls destaca que os próprios cidadãos, voltando-se para suas doutrinas abrangentes, podem relacionar a concepção política como derivada de outros valores seus, ou congruentes com eles, ou pelo menos não contraditórios com tais valores. Contudo, ele esclarece que uma concepção política de justiça é formulada como uma visão que se sustenta por si própria, o que não significa que uma concepção política não possa coincidir com doutrinas abrangentes ou mesmo contradizê-las, como vimos antes.

Rawls afirma que, na razão pública, é possível permitir que se introduza na discussão política nossa doutrina abrangente, religiosa ou não, contanto que ofereçamos razões adequadamente públicas para apoiar os princípios e as políticas que se acredita que nossa doutrina abrangente sustente. Embora a visão ampla da cultura política pública permita introduzir, por exemplo, uma parábola do Evangelho, a razão pública exige que justifiquemos nossa proposta com base em valores políticos adequados, isto é, não metafísicos.

Interessante é perceber que, num primeiro momento, Rawls, no Liberalismo Político, argumenta que, diante de impasses na ordem do político, os cidadãos não podem recorrer às razões mais fundamentais de suas doutrinas abrangentes. Ele destaca que os cidadãos deveriam votar com referência numa ordenação de valores políticos, e não metafísicos. Numa 
palavra, Rawls enfatiza ser desejável que as diversas doutrinas abrangentes sejam deixadas de lado na razão pública.

A tese rawlsiana ressalta sempre o seguinte aspecto: os cidadãos possuem uma identidade pública e outra privada. Na razão pública, as justificações devem ser guiadas por argumentos da ordem da identidade pública. Por outro lado, Rawls afirma que os valores políticos não são totalmente separados de outros valores ou que estejam em descontinuidade com eles. É possível, diz ele, que os cidadãos possam relacionar a concepção política como derivada de outros valores seus e de suas doutrinas abrangentes, mesmo que haja a defesa de uma concepção política de justiça sustentada por si própria (RAWLS, 2011).

Rawls mais uma vez defende que é possível permitir que se introduzam, na razão pública, nossas doutrinas abrangentes, desde que ofereçamos razões adequadamente públicas para apoiar uma concepção política de justiça. No entanto, podemos identificar algo não esclarecido por Rawls. Ele nem sempre é claro em diferenciar o uso comum que os indivíduos fazem a partir de suas doutrinas abrangentes e o contexto onde efetivamente podem tomar decisões de caráter público que atinja a todos os cidadãos, deixando as doutrinas abrangentes de lado.

Habermas (2007) concorda que seja possível introduzir, nas deliberações públicas, nossas doutrinas abrangentes, desde que traduzidas para uma linguagem secular no parlamento. Porém, ele discorda de Rawls, quando este defende a estratégia de separar rigidamente nossa identidade pública da privada. Habermas considera que a necessária exigência da separação entre religião e política não deve resultar, como em Rawls, num fardo adicional indevido que exige uma partição da identidade num aspecto público e noutro privado, em relação aos crentes e religiosos.

Segundo Habermas, essa assimetria impõe custos desigualmente distribuídos para os crentes, prejudicando as condições simétricas de participação na democracia deliberativa. Portanto, haveria, em Rawls, um fardo injusto para os crentes, ao terem que separar suas identidades entre religiosa e não religiosa, algo inconcebível para Habermas. Poderíamos dizer que muitos cidadãos religiosos colocariam em jogo suas existências piedosas. Habermas argumenta que temos que levar em conta a posição que a religião assume na vida das pessoas crentes: o sujeito piedoso encara sua existência a partir da fé. Esta não é apenas uma doutrina ou conteúdo no qual se crê, mas, igualmente, uma fonte de energia da qual se alimenta a vida inteira um crente (HABERMAS, 2007). 
Para Habermas, a ideia segundo a qual todos os cidadãos devem deixar-se conduzir por considerações seculares, "não tem nada a ver, em última instância, com a realidade de uma existência conduzida pela fé" (HABERMAS, 2007, p. 146). O Estado liberal que protege de igual modo todas as formas religiosas de vida, não pode obrigar os cidadãos religiosos a separar estritamente identidades religiosas de não religiosas. Aos olhos dos crentes isto pode constituir um ataque às suas identidades pessoais.

O Estado liberal possui, evidentemente, um interesse na liberação de vozes religiosas no âmbito da esfera pública política, bem como na participação política de organizações religiosas. Ele não pode desencorajar os crentes nem as comunidades religiosas de se manifestarem também, enquanto tal, de forma política, porque ele não pode saber de antemão se a proibição de tais manifestações não estaria privando, ao mesmo tempo, a sociedade de recursos importantes para a criação de sentido. (HABERMAS, 2007, p. 148)

A concepção de justiça dos crentes lhes ensina o que é politicamente correto ou incorreto. Desta forma, o Estado liberal, que protege as formas de vida dos religiosos mediante a garantia da liberdade de religião, não pode exigir, ao mesmo tempo, que os crentes fundamentem seus posicionamentos políticos, deixando inteiramente de lado suas convicções religiosas ou metafísicas sobre o mundo, tal qual sugere Rawls. Para Habermas, haveria nisso uma sobrecarga mental e psicológica insuportável para os religiosos, prejudicando as necessárias condições simétricas de participação na democracia deliberativa entre crentes e não crentes.

Ao participarem das discussões públicas, cidadãos religiosos podem reconhecer que a reserva da tradução do idioma religioso para o secular, como propõe Habermas, não constitui divisão de suas identidades em partes privadas e públicas. O Estado liberal não pode obrigar os cidadãos religiosos a separarem estritamente suas identidades entre religiosas e não religiosas.

Os religiosos devem reconhecer que o princípio do exercício do poder é neutro do ponto de vista das visões de mundo. Eles precisam saber e aceitar que, nas instituições, parlamentos, tribunais e ministérios, apenas contam argumentos seculares.

No parlamento, diz Habermas, deve-se retirar da ordem do dia posicionamentos ou justificativas religiosas. Isto não significa que a religião não possa orientar os indivíduos. Entretanto, deve-se traduzir, como explicitamos antes, as intuições religiosas para argumentações seculares no parlamento (HABERMAS, 2007). Diferentemente de Rawls, 
Habermas defende que a tradução do idioma religioso para o secular não implica em uma separação rígida entre identidade religiosa e não religiosa.

Rawls, tal qual vimos antes, sempre tem em mente a posição original como referência, pensando um sujeito a priori da intersubjetividade, dos contextos formadores das identidades e dos processos de socialização. Não por acaso ele defende uma separação estrita entre identidade privada e pública. Já para Habermas faz parte das convicções religiosas dos crentes o fato de que eles devem basear suas decisões de acordo com suas convicções religiosas. Eles não podem ver isso como uma opção qualquer entre fazer ou não fazer certas coisas. Do ponto de vista do crente, há um esforço para atingir a completude e a integridade em suas vidas, através da palavra de Deus, do ensino da Torah, dos mandamentos e exemplos de Jesus etc. Isto configura a existência dos crentes, tal qual um todo incluído, bem como a existência social e política dos religiosos (HABERMAS, 2007).

Habermas argumenta, assim, que o conflito sobre a autocompreensão secular da sociedade não pode ser deslocado apenas para os religiosos. O senso comum não é singular, uma vez que se estabelece numa esfera pública plural. Portanto, os seculares não devem chegar a conclusões nos diversos temas, "antes de dar ouvidos à objeção dos oponentes que se sentem lesados em suas convicções religiosas" (HABERMAS, 2013, p. 16).

Os cidadãos religiosos, na esfera pública, segundo Habermas, podem se manifestar em sua própria linguagem. Do contrário, os concidadãos religiosos, nas deliberações públicas, seriam sobrecarregados de modo assimétrico em relação aos secularizados, como há em Rawls. Entretanto, no parlamento, há a ressalva da tradução do idioma religioso para o secular. O fardo da tradução é compensado pela expectativa normativa, segundo a qual os cidadãos seculares se abrem a um possível conteúdo de verdade vindo das religiões. Apesar de não passarem por uma censura na esfera pública, as contribuições religiosas dependem de trabalhos cooperativos de tradução para poderem entrar na pauta de discussão do parlamento.

Nesse sentido, a razão profana, mas não derrotista, mantém, por sua parte e com grande respeito, a brasa sempre suscetível de se tornar chama, quando se coloca a questão da teodicéia para se aproximar da religião. Ela sabe que a passagem do sagrado para o profano começou com as grandes religiões universais, que desencantaram a magia, superaram o mito, sublimaram o sacrifício e revelaram o segredo. Essa ambivalência também pode conduzir à atitude razoável de manter uma certa distância da religião, sem se fechar totalmente às suas perspectivas. (HABERMAS, 2004, p.151-52). 
Entretanto, Habermas reforça a ideia de um Estado de direito neutro do ponto de vista das imagens de mundo, pois somente este está preparado para garantir a convivência tolerante entre crentes das mais diversas religiões e não crentes: a crítica ao secularismo não deve "abrir as portas para revisões que venham a anular a separação entre Igreja e Estado" (HABERMAS, 2007, p. 140).

\section{CONCLUSÃO}

Como vimos, em Rawls, os cidadãos são razoáveis à medida que veem uns aos outros como livres e iguais em um sistema de cooperação social que existe ao longo das gerações, oferecendo termos equitativos de cooperação social e concordando em agir com base nesses termos. O poder político é apropriado somente quando podemos supor que as razões que oferecemos para nossa ação política possam ser razoavelmente aceitas por seculares e religiosos. Então, os cidadãos não podem recorrer às razões mais fundamentais de suas doutrinas abrangentes.

Contudo, Habermas critica a estratégia rawlsiana de separar, num mesmo indivíduo, uma identidade pública de uma privada. Ele opta por uma tradução do idioma religioso para o secular, sem desprezar o contexto formador das identidades dos sujeitos. Na perspectiva habermasiana, não há uma separação estrita entre identidade pública e privada, como existe em Rawls.

Ao participarem das discussões públicas, cidadãos religiosos podem reconhecer que a reserva da tradução do idioma religioso para o secular não constitui uma divisão entre identidades privadas e públicas. O Estado liberal não pode obrigar os cidadãos crentes, ainda na esfera pública, a separarem estritamente entre argumentos religiosos e não religiosos. Tal exigência apenas poderá ser dirigida aos políticos que assumem mandatos públicos ou pretendem assumir. Eles "são obrigados a adotar a neutralidade no que tange às visões de mundo" (HABERMAS, 2007, p. 145).

De um lado, os religiosos devem reconhecer que o princípio do exercício do poder é neutro do ponto de vista das visões de mundo. Eles precisam saber e aceitar que, nas instituições, parlamentos, tribunais e ministérios, apenas contam argumentos seculares. Por outro lado, os seculares não podem a priori descartar as intuições éticas das religiões, que devem ser traduzidas para uma linguagem pública e secular no parlamento, ocorrendo um processo de aprendizagem complementar entre secularismo e religião (HABERMAS, 2007). 


\section{REFERÊNCIAS}

FORST, R. Contextos da justiça: Filosofia Política para além de liberalismo e comunitarismo. São Paulo: Boitempo Editorial, 2010.

HABERMAS, J. Pensamento pós-metafísico: Estudos Filosóficos. Rio de Janeiro: Tempo Brasileiro, 1990.

HABERMAS, J. Comentários à ética do discurso. Lisboa: Instituto Piaget, 1991.

HABERMAS, J. A inclusão do outro: Estudos de Teoria Política. São Paulo: Edições Loyola, 2002.

HABERMAS, J. O futuro da natureza humana: a caminho de uma eugenia liberal? São Paulo: Martins Fontes, 2004.

HABERMAS, J. Entre naturalismo e religião: estudos filosóficos. Rio de Janeiro: Tempo Brasileiro, 2007.

HABERMAS, J. Fé e saber. São Paulo: Unesp, 2013.

OLIVEIRA, M. O Debate acerca da fundamentação de uma Teoria da justiça: Rawls e Habermas. In: FELIPE, S. Justiça como equidade: fundamentação e interlocuções polêmicas (Kant, Rawls e Habermas). Florianópolis: Editora Insular, 1998.

RAMOS, C. A crítica comunitarista de Walzer à Teoria da justiça de John Rawls. In: FELIPE, S. Justiça como equidade: fundamentação e interlocuções polêmicas (Kant, Rawls e Habermas). Florianópolis: Editora Insular, 1998.

RAWLS, J. Uma Teoria da justiça. 3.ed. São Paulo: Martins Fontes, 2008.

RAWLS, J. O liberalismo político. São Paulo: Martins Fontes, 2011.

WERLE, D. Construtivismo não metafísico e reconstrução "pós-metafísica": o debate RawlsHabermas. In: NOBRE, M; REPA, L. Habermas e a reconstrução. Campinas: Papirus Editora, 2012. 